\title{
Derecho alimentario entre cónyuges
}

Carmen Julia CABELLO*

Es objetivo de estas líneas propiciar la reflexión crítica en relación a algunos aspectos controvertidos del régimen jurídico del derecho alimentario entre cónyuges y sus repercusiones en la práctica judicial.

El presente comentario hará referencia al marco normativo sobre el derecho alimentario entre cónyuges y sus antecedentes en nuestra legislación, para luego contrastarla con algunas fórmulas judiciales empleadas usualmente en materia de alimentos en los procesos de separación de cuerpos y divorcio, que presentan un tratamiento judicial diferenciado a nivel nacional, lo que plantea la necesidad de su debate jurídico.

\section{Aspectos legislativos}

Es el artículo $474^{\circ}$ del Código Civil, el que preceptúa que los cónyuges se deben recíprocamente alimentos.

La relación alimentaria entre el marido y la mujer es consecuencia de otra mayor, el "deber de asistencia» consagrado también en el artículo 288 del citado cuerpo de leyes.

Cierto es, como bien lo expresa el maestro Cornejo Chávez que:

«Por el matrimonio surge una alianza vigente para todos los efectos de la vida y por la que cada uno ha de velar porque el otro atienda y satisfaga sus necesidades $»^{1}$

* El presente ensayo fue una ponencia de la autora en el evento Realidad Jurídica de la Mujer en el Perú, organizado por la Academia de la Magistratura, Cajamarca, octubre 1996.

Cornijo Chávliz, Héctor, Derecho Familiar Peruano; Studium, 1985, p.238. 


\section{Antecedentes legislativos}

Al igual que en el Código Civil vigente, el de 1936 consagraba en su artículo 441 que los cónyuges se deben alimentos recíprocamente. No obstante lo cual, la sistemática legislativa en la que se encontraba inserto este precepto, se planteaba en términos distintos, como puede advertirse:

Artículo 164.- «El marido está obligado a suministrar a la mujer y en general a la familia, todo lo necesario para la vida, según sus facultades y situación»

Articulo 165.- "Cesa la obligación de alimentar a la mujer cuando abandona la casa conyugal sin justa causa y rehúsa volver a ella.

En este caso, el juez puede, según las circunstancias ordenar el embargo parcial de las rentas de la mujer, en beneficio del marido y de los hijos».

Seguidamente; el artículo $288^{\circ}$ disponía en los casos de divorcio y separación de cuerpos que :

«El Juez señalará en la sentencia de divorcio o de separación la pensión alimenticia del cónyuge, y la de los hijos, cuidando de que ambas queden aseguradas. Esta asignación subsistirá mientras no se modifique en el juicio que corresponda».

Al respecto se comprendió uniformemente y por mucho años, que el Juez debía señalar una pensión alimenticia a favor de la cónyuge, aunque no haya sido convenida o demandada, fijándose incluso montos simbólicos, para no incurrir en sanción de nulidad. Reiterada jurisprudencia así lo dispuso. ${ }^{2}$

Posteriomente el numeral 11 del artículo $12^{\circ}$ del Decreto Legislativo 310 , que regulaba los aspectos procesales del entonces novísimo Código

2 Ejecutoria Suprema del 2 de setiembre de 1963.

Ejecutoria Suprema del 7 de julio de 1982.

Ejecutoria Suprema del 27 de diciembre de 1984.

En Cabillo, Carmen Julia; Diporcio y Jurisprudencia en el Perú; Fondo Editorial Pontificia Universidad Católica del Perú, 1995, p. 417. 
Civil, expresaba: «El juez señalará en la sentencia de separación de cuerpos, la pensión alimenticia del cónyuge y de los hijos, cuidando que ambas obligaciones queden aseguradas».

Hoy nos encontramos frente a dos dispositivos en esta materia, el Art. $342^{\circ}$ del Código Civil : «El juez señala en la sentencia la pensión alimenticia que los padres o uno de ellos debe abonar a los hijos, así como la que el marido debe pagar a la mujer o viceversa", y el Art. $483^{\circ}$ del Código Procesal Civil, que contempla la acumulación originaria de pretensiones en los casos de divorcio o separación de cuerpos por causal. Se establece de manera imperativa que "Salvo que hubiera decisión judicial firme, deben acumularse a la pretensión principal de separación o de divorcio, las pretensiones de alimentos, tenencia y cuidado de los hijos, suspensión o privación de la patria potestad, separación de bienes gananciales y las demás relativas a derechos u obligaciones de los cónyuges o de éstos con sus hijos o de la sociedad conyugal, que directamente deban resultar afectadas como consecuencia de la pretensión principal».

Corresponde preguntamos entonces, si el alcance interpretativo de estas normas pueden en la actualidad ser similar al establecido por la práctica judicial tradicional, inquietud que surge por cuanto no es necesariamente uniforme el criterio judicial nacional en esta materia.

Al respecto resulta conveniente hacer referencia a algunos instrumentos legislativos que deben ser considerados al momento de realizar este proceso de interpretación:

1.- Convención sobre la eliminación de todas las formas de discriminación contra la mujer (ratificada por el Perú el 20 de agosto de 1982). Seguidamente se consignarán algunos artículos vinculados a la dogmática del tema en tratamiento:

Articulo 2.- Los estados partes condenan la discriminación contra la mujer en todas sus formas, convienen en seguir, por todos los medios apropiados y sin dilaciones, una política encaminada a eliminar la discriminación contra la mujer.

a) Consagrar, en sus constituciones nacionales y en cualquier otra legislación apropiada el principio de la igualdad del hombre y de la mujer

c) Establecer la protección jurídica de los derechos de la mujer sobre una base de igualdad con los del hombre y garantizar, por conducto de los tribunales nacionales competentes y de 
otras instituciones públicas, la protección efectiva de la mujer contra todo acto de discriminación.

Articulo 4.- La adopción por los estados partes de medidas especiales de carácter temporal encaminadas a acelerar la igualdad de facto entre el hombre y la mujer no se considerará discriminación en la forma definida en la presente Convención, pero de ningún modo entrañará, como consecuencia, el mantenimiento de normas desiguales o separadas; estas medidas cesarán cuando se hayan alcanzado los objetivos de igualdad, de oportunidad y trato.

Artículo 5.- Los estados partes tomarán todas las medidas apropiadas para:

a) Modificar los patrones socioculturales de conducta de hombres y mujeres, con miras a alcanzar la eliminación de los prejuicios y las prácticas consuetudinarias y de cualquier otra índole que estén basados en la idea de la inferioridad o supcrioridad de cualquiera de los sexos o en funciones estereotipadas de hombres y mujeres.

Articulo 15.- Los estados partes reconocerán a la mujer la igualdad con el hombre ante la ley.

Los estados partes reconocerán a la mujer, en materias civiles, una capacidad jurídica idéntica a la del hombre y las mismas oportunidades para el ejercicio de esa capacidad. En particular, le reconocerán a la mujer iguales derechos para firmar contratos y administrar bienes y le dispensarán un trato igual en todas las etapas del procedimiento en las cortes de justicia y los tribunales.

Articulo 16.- Los estados partes adoptarán todas las medidas adecuadas para eliminar la discriminación contra la mujer en todos los asuntos relacionados con el matrimonio y las relaciones familiares y, en particular, asegurarán, en condiciones de igualdad entre hombres y mujeres:

a) El mismo derecho para contraer matrimonio;

c) Los mismos derechos y responsabilidades durante el matrimonio y con ocasión de su disolución;

h) Los mismos derechos a cada uno de los cónyuges en materia de 
propiedad, compras, gestión, administración, goce y disposición de los bienes, tanto a título gratuito como oneroso.

\section{Constitución Política de 1979 y 1993:}

Constitución de 1979: El varón y la mujer tienen iguales oportunidades y responsabilidades. La ley reconoce a la mujer derechos no menores que el varón.

Constitución de 1993: Se señala simplemente el artículo 2 inciso 2, toda persona tiene derecho a la igualdad ante la ley: Nadie debe ser discriminado por motivo de origen, raza, sexo....

Igualdad que creemos ha de interpretarse como igualdad SUSTANCIAL o material, acorde a los tratados y convenios en materia de derechos humanos, aplcándose la Convención de los Derechos de la Mujer.

\section{Código Civil de 1984}

Sistemática del Libro de Familia

Artículo 234 El marido y la mujer tienen en el hogar, autoridad, consideraciones, derechos, deberes y responsabilidades iguales.

Artículo 288.- Deber de fidelidad y asistencia recíproca.

Articulo 289.- Deber de cohabitación.

Articulo 290.- Igualdad en el gobierno del hogar y fijación y mudación del domicilio conyugal.

Articulos 291 - 300.- Obligación conjunta de sostener a la familia. Excepción quien se dedique al cuidado del hogar.

Articulo 292.- Representación de la sociedad conyugal ejercitada conjuntamente por los cónyuges; poder parcial o total.

Artículo 293.- Libertad de trabajo de los cónyuges.

Articulo 195.- Libertad en la elección del régimen patrimonial por los cónyuges. 
Articulo 313.- Corresponde a ambos cónyuges la administración del patrimonio social.

Artículo 419.- La patria potestad se ejerce conjuntamente por el padre y la madre durante el matrimonio, correspondiendo a ambos la representación del hijo.

\section{Código Procesal Civil}

Artículo 65.- La sociedad conyugal y otros patrimonios autónomos son representados por cualquiera de sus partícipes si son demandantes.

Si son demandados la representación recae en la totalidad de los que la conforman. Es de aplicación el artículo 93 del Código Procesal Civil (Litis Consorcio Necesario)

Dado este marco legislativo refencial y sobre todo la FILOSOFIA que subyace en él, reflexionemos en torno a la regulación de la obligación alimentaria entre cónyuges en los procesos de separación de cuerpos y divorcio hoy.

\section{Práctica judicial}

A continuación presentaremos algunas fórmulas judiciales tipo, a partir de las cuales se propondrán algunos comentarios.

Caso 1 Renuncia de la cónyuge a los alimentos.

Habiendo la cónyuge renunciado expresamente a los alimentos no se fija pensión alimenticia a favor de ésta en la sentencia de separación de cuerpos convencional.

Caso 2 La cónyuge no renuncia expresamente a los alimentos.

En los procesos de separación de cuerpos convencional, no habiendo la cónyuge renunciado expresamente a los alimentos corresponde al juez fijar una pensión de alimentos a su favor.

Caso 3 Cese de los alimentos fijados de oficio.

Como en la sentencia de divorcio se dispuso subsista lo dispuesto en la resolución de separación de cuerpos, continúa la pensión alimenticia, señalada de oficio, el cónyuge solicita en 
vía incidental el cese de la obligación alimentaria, resolviéndose que corresponde hacerlo por vía de acción.

Caso 4 No puede fijarse alimentos de oficio cuando la cónyuge no los ha demandado.

Caso 5 Subsiste la prestación alimentaria incluso luego del divorcio, porque existe un convenio al respecto.

Caso 6 Se señala un monto global de pensión alimenticia a favor de la cónyuge y de los hijos.

\section{Comentario:}

Eduardo Ignacio Fanzolato sotiene que el derecho-deber de alimentos entre marido y mujer se origina y fundamenta en el vínculo matrimonial que los emplaza en el estado de familia de cónyuges $^{3}$, por ello resulta pertinente preguntarnos si como en el primer caso planteado, la o el cónyuge pueden renunciar a su derecho alimentario, que como tal es irrenunciable, personalísimo, imprescriptible, incompensable, intransigible. Consideramos que esta expresión judicial y forense continuamente utilizada, de ser empleada debe referirse única y exclusivamente a la renuncia de la prestación alimentaria, que en todo caso no afecta al derecho alimentario en sí, que subsiste por mandato legal para los cónyuges durante el matrimonio, y que éstos son libres de ejercitarlos o no.

Los siguientes casos nos requieren inquirir respecto a la fundamentación jurídica-sociológica de la obligación alimentaria entre cónyuges, y los cambios que se han producido al respecto. Eduardo Zannoni explica que dentro de un enfoque legal paternalista, se conceptúa que el deber de protección que tradicionalmente debe el marido a la esposa, lo es como contraprestación del deber de obediencia de ésta, en función de la clásica potestad marital. El concepto de potestad marital era correlativo al status de incapacidad de hecho de la mujer casada y su representación necesaria por el marido.

Hoy la protección no virtualiza sólo un deber que pesa sobre el marido, sino que está contenida en los componentes de la asistencia que se deben mutuamente los esposos, situados uno frente al otro en un plano de existencia y jurídico de igualdad. ${ }^{4}$

3 FanzoLATO, Eduardo; Alimentos y reparacioner en la separacion y divorcio, Buenos Aires, Depalma, 1991, p 12.

4 Zannoni, Eduardo; Divorcio y Obligación Alimentaria entre cónyuges; Buenos Ai res, Astrea, 1977, ps. 18 y 19. 
Como ya se refiriera líneas arriba, la evolución legislativa que ha impregnado el desarrollo de las instituciones del derecho familiar a nivel formal, aunque discutible a nivel real, cuestionan la continuidad de prácticas judiciales que se fundamentaban en un esquema jurídico distinto al vigente, es el caso de la fijación de oficio de alimentos a la cónyuge, cuando no ha renunciado expresamente a la prestación

Conviene distinguir en materia de alimentos entre cónyuges varios supuestos:

I- Cuando lo cónyuges hacen vida común

2- El caso de que vivan separados de hecho

3- El período durante el cual se gestiona la separación judicial o el divorcio

4-Una vez pronunciada la sentencia de divorcio.

1) En el supuesto de vida normal en común es dificil observar el contorno nítido de los alimentos, como deber jurídico independiente, al estar absorbido en la plena comunidad de existencia de la pareja. Satisfacen naturalmente y sin ser requeridos, todos los deberes matrimoniales. Son de aplicación el artículo $291^{\circ}$ y $300^{\circ}$ del Código Civil y de no ser así, cualquiera de los cónyuges puede requerirlo judicialmente, mediante la demanda de alimentos correspondientes.

2) En el caso de que vivan separados de hecho. El matrimonio perdura y no se ha operado ninguna transformación legal en los derechos ni en las obligaciones de los cónyuges, que son indisponibles y surgen del vínculo. Si uno a actuado con malicia, la conducta antijurídica en que incurrió no puede servir de título para liberarlo de sus deberes. Es más, la víctima no está obligada a deducir acción de separación o divorcio a fin de obtener alimentos. El artículo $291^{\circ}$, segundo párrafo del Código Civil, prevé el caso de quien se apartó de la casa común injustificadamente y exija alimentos al otro cónyuge, estableciéndose que cesa la obligación alimentaria en este caso.

El asunto que se plantea al tratar este artículo, es si dicho dispositivo debe ser argumento de defensa para exceptuarse de prestar una pensión de alimentos al cónyuge abandonante, en un proceso regular de alimentos, o si por el contrario este derecho debe de hacerse valer en acción independiente.

Al respecto la doctrina argentina sostiene:

Mientras no se pronuncie una decisión judiciaria, declarando culpabilidades, ellas no existen para el orden positivo. El que se autotitula «inocente» sólo quedará emplazado legalmente en esa calidad en virtud de 
una sentencia de separación o de divorcio, dictada en un procedimiento contencioso. Si uno de los cónyuges separados de hecho, basado en su pretendida inocencia, busca excepcionarse de los deberes alimentarios que le conciernen, tiene dos recursos para conseguir ese propósito.

a) Apelar al juicio contencioso de separación o de divorcio.

b) Lo faculta para requerir judicialmente que se intime al otro a reanudar la convivencia interrumpida sin causa justificada, bajo apercibimiento de negarle la prestación alimentaria. Semejante intimación no puede ser planteada, por vía reconvencional, en el proceso sumario de fijación provisoria de alimentos, sino que se deberá interponer una demanda ordinaria con esa finalidad, y el cónyuge requerido que se dice «inocente» deberá cumplir, mientras tanto, sus obligaciones alimentarias. ${ }^{5}$

De lo expresado, podemos concluir que en los casos de separación de hecho, se mantiene subsistente la obligación alimentaria recíproca entre cónyuges, a excepción de la separación de hecho unilateral prevista por el artículo $291^{\circ}$ del Código Civil, frente a la cual coincidimos con la necesidad de que debe ser materia de debate judicial en un proceso distinto al sumarísimo de alimentos.

1) Es necesario distinguir entre los procesos de divorcio y separación por causal y los de separación de cuerpos convencional y ulterior divorcio.

En los casos de acciones por causal, de acuerdo a los dispuesto por el artículo $483^{\circ}$ del Código Procesal Civil «debe» acumularse a la pretensión principal de separación o de divorcio las pretensiones de alimentos, entre otros. Por lo que la legislación procesal requiere la petición expresa y acumulada de alimentos, facultando la procedencia de medidas cautelares en esta materia, como lo es la asignación provisional de alimentos durante el proceso. Es más, en la Audiencia Conciliatoria o de fijación de puntos controvertidos y sancamiento probatorio, debe de consignarse como punto de controversia independiente del referido a la, o las causales objeto de debate judicial, uno relativo a la fijación del monto o porcentaje de la prestación alimentaria solicitada, a fin de que se admitan los medios probatorios vinculados a esta materia en particular que contribuyan a ilustrar el criterio del juez, y que muchas veces en los pleitos de divorcio son postergados por las partes, en la vorágine probatoria que atrae el debate judicial de las causales de divorcio o

: Fanzolato, Eduardo; op. cit.; p. 20. 
separación; dificultándose la tarea del juzgador al momento de fijar la pensión alimenticia.

De no accionar los cónyuges en este aspecto, y como el artículo 342 del Código Civil conmina al juez a que en la sentencia de divorcio o separación de cuerpos señale la pensión de alimentos que los padres o uno de ellos debe abonar a los hijos, así como la que el marido debe pagar a la mujer o viceversa; tratándose de menores y en aras del interés superior del niño y del adolecente, consagrado por el artículo VIII del Título Preliminar del Código de los Niños y Adolescentes, el Juez de Familia ha de considerar el petitorio incompleto ordenando la subsanación del defecto, en salvaguarda del derecho alimentario de éstos. En el caso de los cónyuges es distinto, se trata de sujetos capaces, por lo que sería conveniente en todo caso dejar constancia en la audiencia correspondiente de que el demandante no peticiona pensión de alimentos a su favor, no pudiendo el A-quo señalar pensión alimenticia que no ha sido materia de petitorio. Es del caso considerar que el derecho alimentario del cónyuge cuya separación o divorcio se está ventilando, subsiste en tanto se mantenga el vínculo matrimonial, encontrándose expedito su derecho a ejercitarlo judicialmente, correspondiéndole acreditar sus necesidades como solicitante y las posibilidades del obligado.

De otro lado, en los casos de separación convencional es fundamental la propuesta de convenio, firmada por los cónyuges que regulan entre otros el régimen de alimentos de éstos y los menores.

El Juez no acogerá el contenido del convenio si éste no asegura adecuadamente la obligación alimentaria, los deberes inherentes a la patria potestad y los derechos de los menores e incapaces. En ese entendido bien pueden los cónyuges expresar su voluntad de no desear percibir pensión de alimentos del otro cónyuge, como también podrán omitirlo, no regulándolo expresamente y ello constituye el ejercicio libre del derecho de no ejercitar un derecho, en ese sentido el juez no puede compeler a dos sujetos capaces para que uno de ellos sea acreedor de una pensión alimenticia que no necesita o en última instancia no desea, y que en todo caso de necesitarla o quererla, tiene expedito los recurso legales para hacerla valer, por lo que consideramos que a la luz del sistema alimentario vigente entre cónyuges, no es posible la fijación de oficio de una pensión alimenticia a favor de uno de los cónyuges que no ha sido peticionada, o materia de convenio .

Otro aspecto que creemos resulta aún más preocupante en la práctica, son los términos en los cuales se propone el régimen de alimentos en el aludido convenio, que por lo general se limita a señalar un monto o porcentaje a favor de uno de los cónyuges y de los hijos menores, en al- 
gunos casos distinguiendo las asignaciones por alimentista, y en otros fijando un monto o porcentaje global para la prestación.

En este aspecto es importante considerar que durante el período comprendido entre la demanda y la declaración de la disolución del vínculo, los alimentos entre cónyuges son obligatorios y tienen su fuente obligacional en la ley. Ellos tan sólo están regulando su cumplimiento en el convenio, pero luego de la disolución, por mandato también de ley, artículo $350^{\circ}$ del Código Civil, se establece como regla que los ex cónyuges no se deben alimentos entre sí, excepto dos supuestos específicos que se tratarán más adelante. Por tanto, como puede comprenderse, resulta de particular importancia el texto del convenio entre los cónyuges que puede dirigirse a regular tres situaciones:

- La no fijación de pensión alimenticia a favor de los cónyuges.

- Establecer la pensión de alimentos que uno de ellos prestará al otro mientras sea su cónyuge.

- Fijar un régimen de alimentos a favor de uno de ellos, para el período que dure el proceso, y que se prolongará luego de la disolución del vínculo.

En este último caso ya no es la fuente legal sino la convencional la que establece la subsistencia de la pensión alimenticia, pese a la-disolución del vínculo. Si ese es el propósito de las partes, primero debe hacerse explícito en el convenio y, como es natural, regularse claramente los montos, incrementos, porcentajes y demás condiciones en la que deba cumplirse la prestación, luego el divorcio.

En los casos en que se establezca pensión de alimentos a favor de varios alimentistas debe discriminarse sus asignaciones de modo individual, a fin de evitar problemas y juicios innecesarios a futuro, cuando cese, se extinga o se configure algún supuesto de exoneración de la obligación alimenticia contra alguno de ellos.

Suele advertirse en la práctica forense que los cónyuges acuerdan una pensión de alimentos a favor de uno de ellos, en términos puros y simples, sin añadir ningún tipo de aclaración en el convenio anexo a la demanda de separación de cuerpos. Luego este es acogido por la sentencia que declara la separación. Posteriormente, a los seis meses, solicitada la conversión, la sentencia de divorcio dispone asimismo subsistan los acuerdos materia de convenio incoporados en la sentencia de separación. Finalmente este fallo en consulta es aprobado por el Tribunal Superior. Se trata pues de una práctica judicial de más de 50 años, que mantiene una pensión de alimentos luego del divorcio, por el 
solo hecho que fue mencionada en el convenio anexo a la demanda de separación.

En ese entendido estamos frente a una tarea conjunta de abogados y magistrados. Los primeros deben orientar a sus patrocinados para que expresen en términos claros y precisos su voluntad tanto en materia alimentaria como en otros aspectos, porque no hay mejor contrato que aquél que es fácilmente entendible por las partes y no requiere mayor interpretación en su términos. Los magistrados debemos exigir esta necesaria claridad en la expresión de la voluntad de los cónyuges, en el admisorio de la demanda, en la audiencia de conciliación, a fin de que no haya posibilidad de excedernos al aprobar divorcios, cuyo régimen alimentario no necesariamente debería subsistir a posteriori del divorcio, porque no es voluntad de uno o ambos cónyuges.

Exigir términos explícitos al momento de evaluar el convenio que será objeto de aprobación judicial, es una forma más equitativa, si ese es el propósito, de proteger a la eventual parte débil de esta relación, que confiada en una práctica tradicional, puede considerar que se encuentran debidamente aseguradas sus futuras pensiones alimenticias, que pudieron ser acordadas verbalmente, o comprendidas así silenciosamente durante un proceso, que incluso son incorporadas en su fallo de divorcio, para luego estas expectativas desvanecerse cuando en cualquier momento después del divorcio, y como una suerte de espada de Damocles, la contraparte invocando legalmente el artículo 350 del Código Civil logrará el cese de esta obligación.

Luego del divorcio, no será la ley de modo general sino la convención como en este caso o la autonomía de la voluntad de uno de los ex - cónyuges si se diera esa liberalidad, la fuente sustentadora de la «pensión alimenticia» a brindarse.

\section{Luego del divorcio}

El artículo 350 del Código Civil preceptúa, como principio general, que por el divorcio cesa la obligación alimenticia entre los ex-cónyuges, aunque dispone excepcionalmente que:

Cuando el divorcio es declarado por culpa de uno de los cónyuges, el inocente tendrá derecho a percibir alimentos, siempre que concurra alguno de estos requisitos:

- Que carezca de bienes propios o gananciales suficientes.

- Que esté imposibilitado de trabajar. 
- Que no puede subvenir a sus necesidades por otro medio.

El monto de la pensión alimenticia será fijada por el juez, no debiendo exceder a la tercera parte de la renta del obligado.

De otro lado, el ex - cónyuge que se encuentre en estado de indigencia, incluso aquél al que le sea imputable el divorcio, podrá solicitar la prestación de alimentos a quien fue su consorte, medida razonable, por cuanto a pesar de lo acaecido no pueden ser indiferentes a la miseria que padezca uno de ellos.

La obligación alimentaria cesa automáticamente cuando el alimentista contrae nuevo matrimonio. Similar supuesto contenía el artículo 268 del Código Civil de 1936, cuando en su vigencia la jurisprudencia lo interpretó extensivamente, señalando que: «Aunque la ley no ha previsto la situación de la mujer divorciada que contrae relaciones sexuales con otros hombres, es indudable que las disposiciones contenidas en el citado artículo 268 se hacen extensivas a tales casos» ${ }^{6}$.

La naturaleza jurídica de los alimentos, que pueda percibir el cónyuge inocente del divorcio, y allí estamos diferenciando los de los provenientes de los procesos convencionales, se ha sometido a dos opiniones doctrinarias: una que sostiene su carácter estrictamente alimentario, mientras que la otra lo considera indemnizatorio.

«La pensión alimenticia que se concede al esposo vencedor en el pleito es la reparación de un perjuicio injustamente sufrido" ${ }^{7}$.

Eduardo Fanzolato precisará aún más «con disolución del connubio el amplio derecho alimentario jure coniugii se torna imposible, porque los divorciados ya no son cónyuges; pero, como la imposibilidad de que subsista el derecho es imputable a la conducta antijurídica del que dio causa al divorcio, los alimentos conyugales se trasustancian en una prestación compensatoria a favor del inocente que experimenta el perjuicio. Así, por obra del divorcio se pasa del campo del derecho matrimonial a la esfera jurídica patrimonial del resarcimiento, ya que si estamos frente a una reparación de daños causados por un proceder reprochable, la prestación no tiene naturaleza asistencial sino que es substancialmente compensatoria, aunque tenga la «foma» periódica de una renta alimentaria»".

Según este criterio, lo que se pretendería entonces sería indemnizar

Resolución Suprema del 6 de octubre de 1949.

7 Henry Caritant y Ambroise Colin, Curso elemental de Derecho Civil, Tomo I, Instituto Editorial Reus, 1941; p. 734.

s Fanzolato, Eduardo; Op. cit.; pp. $31-32$ 
al cónyuge que, sin culpa suya se ve desprotegido ante la desaparición del deber de socorro. Beneficio que no impide a la víctima solicitar, además, la reparación del daño causado por los hechos que dieron lugar al divorcio.

De otro lado, los que le atribuyen un carácter estrictamente alimentario afirman lo siguiente:

«El precepto no permite autorizar ninguna pensión más que en cuanto el esposo inocente no pueda vivir con los bienes que posea o con los productos que perciba de la liquidación del régimen matrimonial, de donde se ve que la pensión tiene el carácter de alimentos»".

En ese entendido, es el estado de necesidad el que haría justificable su prestación, desaparecido éste, no tendría lugar la obligación, que cesaría también con la muerte del ex- cónyuge obligado.

Nuestro sistema consagra la naturaleza asistencial de la prestación alimentaria entre los ex - cónyuges, en los casos excepcionales regulados por el artículo 350 del Código Civil, que exige para la fijación extraordinaria de alimentos los dos requisitos clásicos de una pretensión alimentaria: necesidad de quien los pide y posibilidad de quien debe prestarlos

De lo expuesto puede establecerse que el régimen alimentario entre los cónyuges durante la vigencia del matrimonio es una obligación legal, recíproca, y eminentemente asistencialista, mientras que una vez disuelto el vinculo matrimonial, desaparece tal obligación legal excepto los dos casos mencionados por el artículo 350 del Código Civil, debiendo por tanto concluir la obligación alimentaria con la declaración de divorcio, excepto que de modo expreso los cónyuges hayan convenido se asigne a uno de ellos una pensión alimenticia que rija también a posteriori de la disolución matrimonial. Por estas razones resulta fundamental la precisión y claridad de los términos del convenio anexo a la demanda de separación convencional, para que las resoluciones judiciales expresen lo estrictamente propuesto por los cónyuges.

No deben alentarse falsas expectativas de vida sustentadas en un "derecho alimentario permanente" y que luego se desvanece frente a una acción judicial de cese, cuyo asidero legal es amparable, por cuanto no existe una obligación convencional que sustente lo contrario. 
Es necesario que los cónyuges conozcan las reglas legales durante y después del proceso, no se pueden crear ficciones, fundándonos en interpretaciones pseudo-benevolentes del régimen legal, pero que no corresponden a la ratio legis del sistema. Pretender conservar una presunción de incapacidad de alguno de los cónyuges en nuestros día no sólo no es legal sino culturalmente inconveniente, en un proceso encaminado a fortalecer relaciones igualitarias entre cónyuges.

Conocer con claridad y oportunamente los alcances legales de su situación real, permite a cada quien prever unilateral o convencionalmente qué debe hacerse.

En este orden de ideas, resulta por demás importante en la hora actual, propiciar el diálogo e intercambio de experiencias entre los miembros de la magistratura especializados e interesados en los temas de familia a nivel nacional, a efectos de propender hacia la unidad de criterio, tan necesaria para resolver asuntos de la trascendencia de los ventilados en esta especialidad. Temas vinculados a la filiación extramatrimonial, prueba de la ADN, hijos alimentistas, son algunos de los temas que han sido tratados en el Pleno Especializado de familia, que se ha llevado a cabo en el mes de noviembre del año próximo pasado, eventos de esta naturaleza permiten enriquecer una práctica judicial de amplia incidencia social, a través del diálogo crítico de sus magistrados; particularmente en un contexto como el actual, de debate jurídico-legislativo, frente a las propuestas de reforma del Código Civil vigente. 